\title{
Skeletal Dysplasia (Non - Sclerosing dysplasias - Part II)
}

\author{
Subbarao K \\ Padmasri Awardee Prof. Dr. Kakarla Subbarao, Hyderabad, India
}

\section{Introduction}

In continuation with Sclerosing Dysplasias (Part I), non sclerosing dysplasias constitute a major group of skeletal lesions including dwarfism syndromes. The following list includes most of the common dysplasias either involving epiphysis, metaphysis, diaphysis or epimetaphysis. These include multiple epiphyseal dysplasia, spondyloepiphyseal dysplasia, metaphyseal dysplasia, spondylometaphyseal dysplasia and epimetaphyseal dysplasia (Hindigodu Syndrome). These are included in dwarfism syndromes.

Dwarfism indicates a short person in stature due to genetic or acquired causes. It is defined as an adult height of less than $147 \mathrm{~cm}$ (4 feet 10 inches).

The average height of Indians is men- $5 \mathrm{ft} 3$ $1 / 2$ inches and women- $5 \mathrm{ft} 0$ inches much less than average American or Chinese people.

Dwarfism syndromes consist of 200 distinct medical entities. In Proportionate Dwarfism, the body appears normally proportioned, but is unusually small. In disproportionate dwarfism, one or more body parts are relatively large or small in comparison to those of the body parts of an average-sized adult. The growth variations in specific areas apparent. This may be divided into

Rhizomelic $=$ root, e.g., bones of the upper arm or thigh, Mesomelic $=$ middle, e.g., bones of the forearm or lower leg, Acromelic $=$ end, e.g., bones of hands and feet and Micromelic $=$ entire limbs are shortened.
Out of 70 dwarfism syndromes, the most common form of dwarfism is achondroplasia. It is a proportionate dwarfism and is rhizomelic in $70 \%$ of the patients. It is autosomal dominant. There is rhizomelic type of short limbs with increased spinal curvature. Skull abnormalities are also noted. The radiographic features are mentioned in Table I.

\section{Table I: Achondroplasia- Radiographic features}

- Large skull with prominent frontal bones and a narrow base.

- The interpedicular distance decreases caudally in lumbar region but with normal vertebral height.

- Posterior scalloping

- The pelvis is square with small sciatic notches and the inlet configuration with classical champagne glass appearance

- Trident hands

- Delayed appearance of carpal bones

- Dumb bell shaped limb bones

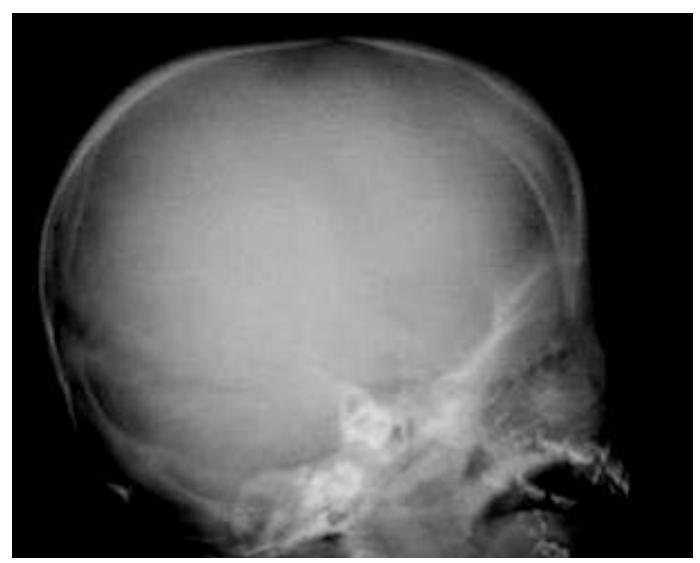

Fig. 1a: Achondroplasia - large skull and narrow base 

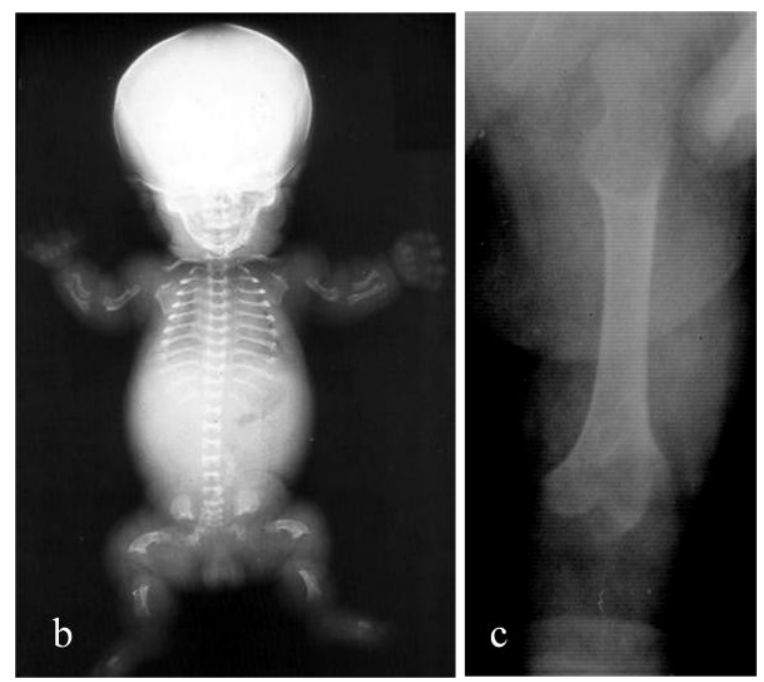

Fig. 1bc: Achondroplasia - b. Body gram of an infant with short limbs, c. Typical dumb bell shaped femur.

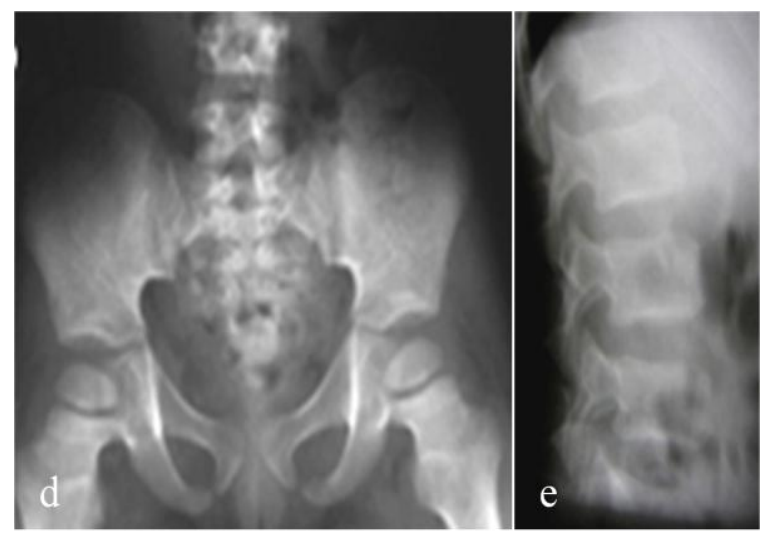

Fig. 1de: Achondroplasia- Spine- Interpedicular spaces. Shorter from lumbar to lumbosacral junction.
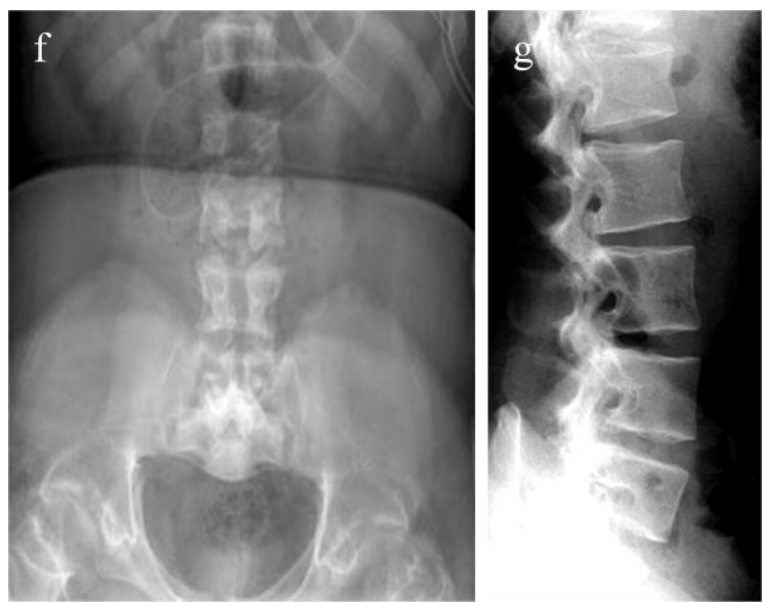

Fig. 1fg: Achondroplasia - Adult spine. Note the posterior scalping of vertebral bodies with a narrow canal.
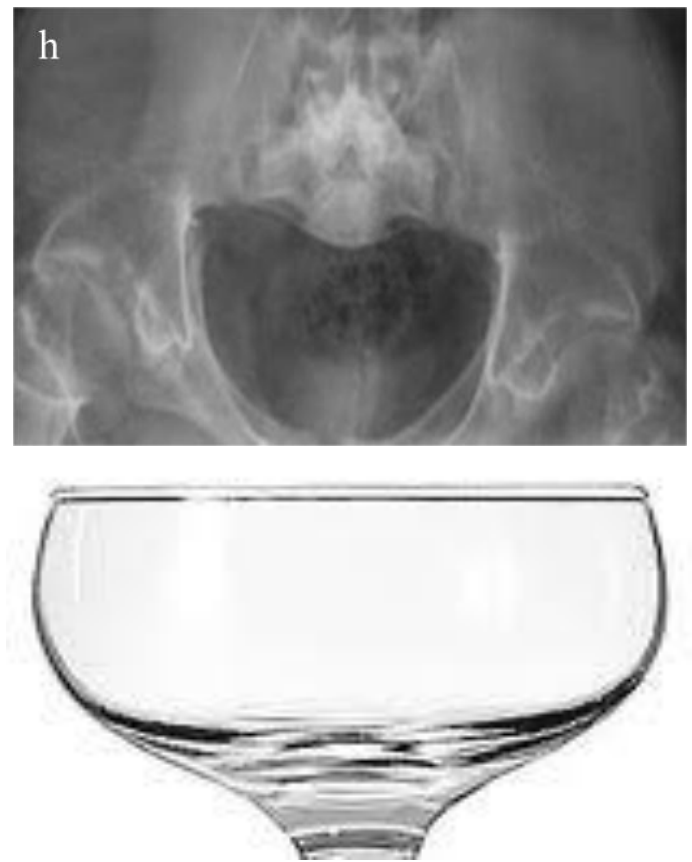

Fig. 1hi: Pelvic inlet shows champagne Glass appearance
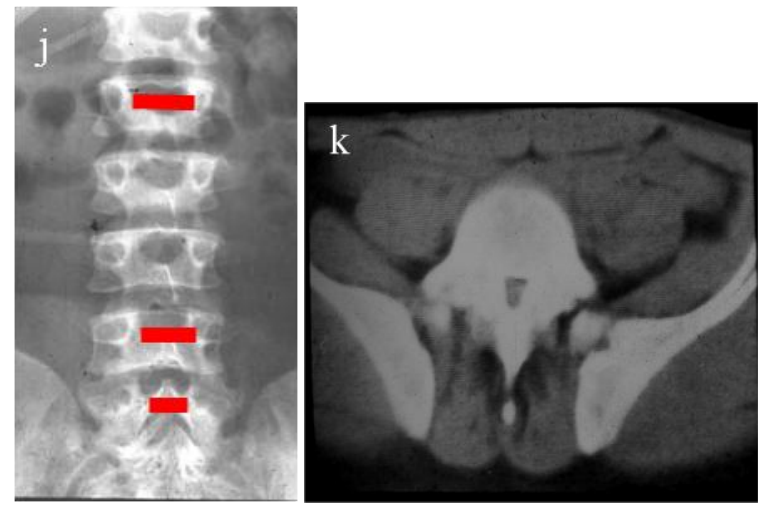

Fig. 1jk: Achondroplasia - Spinal canal stenosis better demonstrated on CT

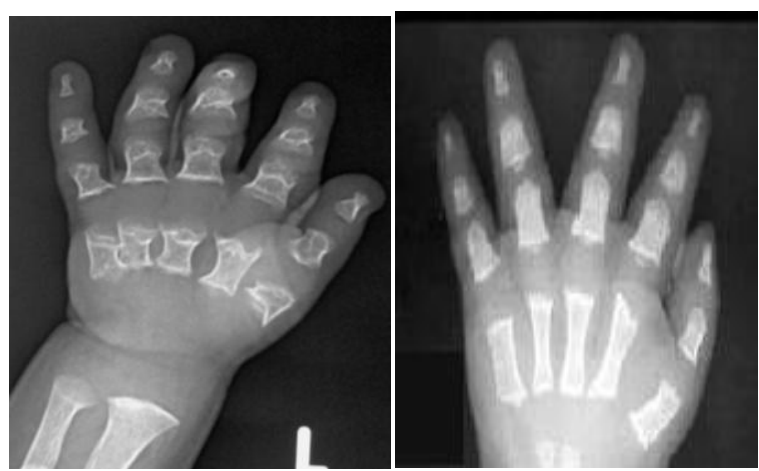

Fig. 1lm: I .infant - Short and stubby metacarpals and phalanges, $m$ - child with Trident hand 


\section{PSEUDO ACHONDROPLASIA}

This type of dwarfism is rare but simulates achondroplasia. The children are of normal intelligence with short limbs. The children are invariably normal at birth, and they usually present either around 2 years of age with a delay in walking or a little later with an abnormal waddling gait. The radiographic features are listed in Table II.

\section{Table II: Pseudo Achondroplasia}

\section{Radiographic Features}

- Shortened bones, proximal more than distal, suggesting rhizomelic type of dwarfism, with flared and irregular metaphysis.

- Epiphyses are small, irregular, and often fragmented with delayed appearance (the femoral capital and humeral epiphysis are most affected).

- Medial beaking of the femoral neck is one of the characteristic features.

- The hand and foot bones (metacarpals, metatarsals and phalanges) are broad and shortened with small and rudimentary epiphysis.

- Pelvis appears squared with broad iliac wings and narrow sacrosciatic notches. The acetabulum is poorly formed with horizontal roofs.

- Skull and facial bones are normal

- Odontoid dysplasia

- Interpedicular distance characteristically normal

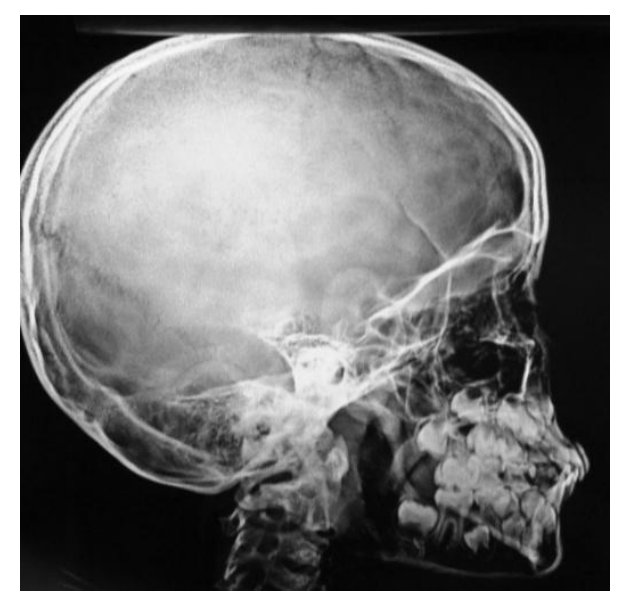

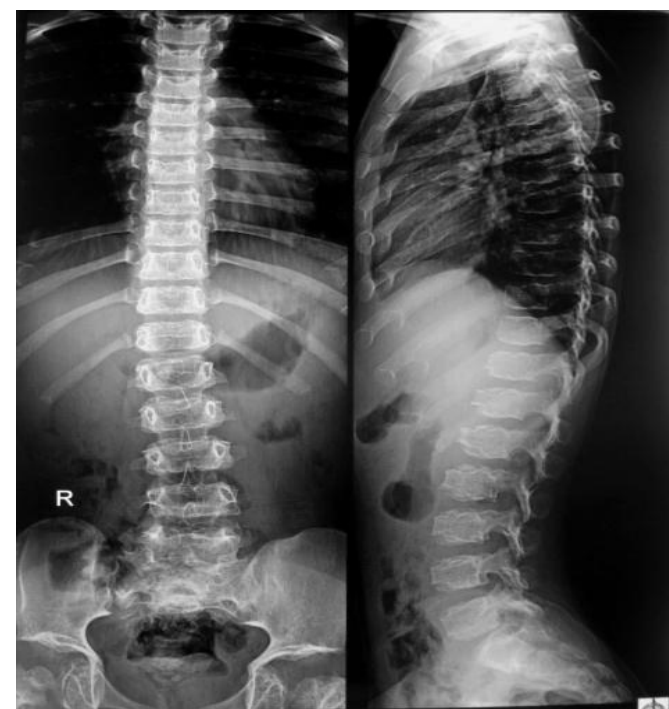

Fig. 2ab: Pseudo Achondroplasia - a. skull $\&$ facial bones are normal, b. Spine Interpedicular distance is characteristically normal.

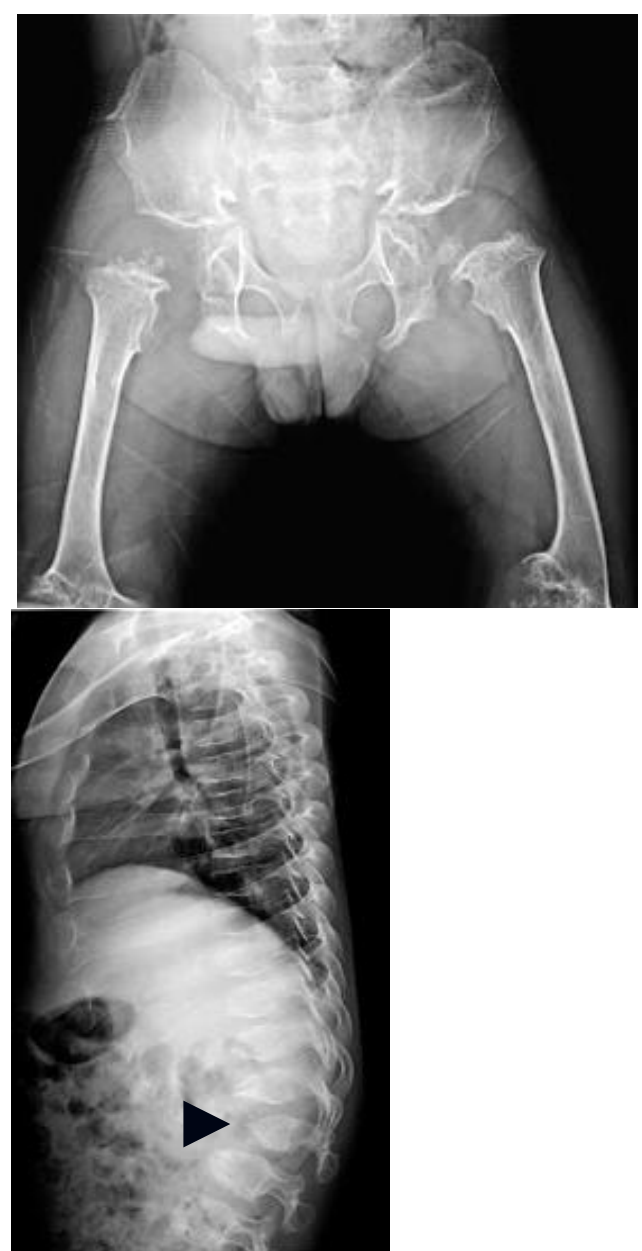

Fig. 2cd: Pseudo Achondroplasia - c. Pelvis similar to achondroplasia, $d$. Hypoplastic L1. 


\section{Lethal Forms of Dwarfism -}

Are diagnosable in utero by ultrasonography

- Homozygous achondroplasia

- Achondrogenesis

- Thanatophoric dwarfism

- Metatrophic dysplasia

Achondrogenesis, it is autosomal recessive, almostly with short trunk and short limbs. Radiographic features (fig. 3) include defective /absent ossification of the vertebrae, pubis and Ischium, grossly shortened tubular bones with metaphyseal irregularities, thin ribs which may show fractures and crescent shaped iliac wings.

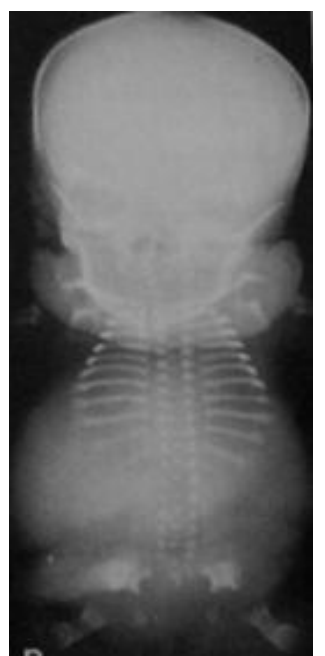

\section{Fig. 3: Achondrogenesis - Body gram of fetus}

\section{Thanatophoric Dysplasia}

It is almost always lethal. Radiological features (fig. 4ab) include flattening of the vertebral bodies and widened disc spaces against a back drop of well formed neural arches-' $\mathrm{H}$ ' or inverted U appearance on AP view.

\section{Metatrophic dysplasia - Can live for a short time}

Characterized by short extremities ,normal trunk at birth,\& short trunk with kyphoscoliosis later in life. Radiographic features (fig. 5ab) include platyspondyly, progressive kyphoscoliosis with hypoplastic odontoid process.
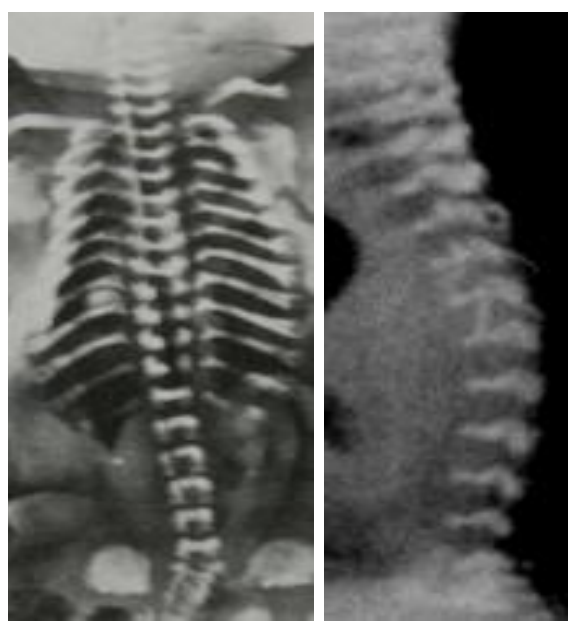

Fig. 4ab: Thanatophoric Dysplasia - Post mortem body gram and spine.

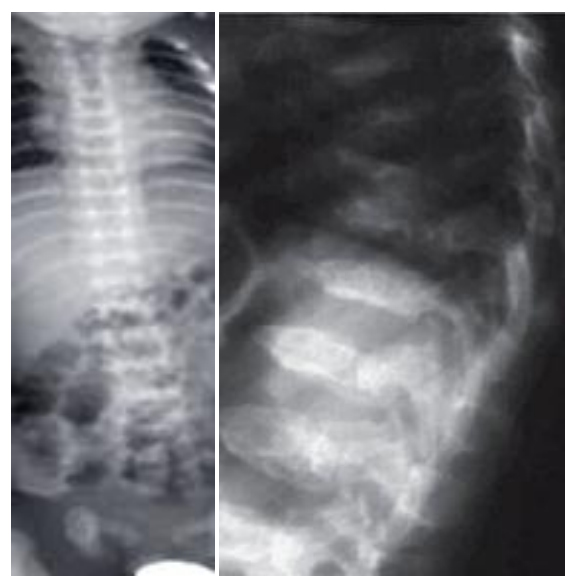

Fig. 5ab: Metatrophic dysplasia - Note platy spondyly and kyphosis.

Other Syndromes are mentioned in table III

\section{Table III}

- Mucopolysaccharodosis - MPS 1 to 7

- Spondyloepiphyseal dysplasia

- Spondylometaphyseal dysplasia

- Osteogensis imperfecta

- Pycnodysostosis

- Chondrodysplasia calcificans congenita

- Chondroectodermal dysplasia

- Hypothyroidism

- Hypochondroplasia

- Diastrophic dysplasia

- Noonan / Turner syndromes

- Primordial dwarfism

- Other storage disorders 


\section{Mucopolysaccharidosis (MPS) (Several Types)}

The mucopolysaccharidosis (MPS) are lysosomal storage disorders caused by the deficiency of enzymes required for the stepwise breakdown of glycosaminoglycans (GAGs), previously known as mucopolysaccharides. An estimated total incidence of all types of MPS of approximately 1 in 20,000 live births. Morquio's syndrome is estimated to occur in 1 of every 200,000 births.

\section{Morquio Syndrome (MPS type IV)}

It is most common MPS and is autosomal recessive. Deposition of excess keratosulfate due to deficiency of $\mathrm{N}$-acetyl galactosamine6-sulfatase. There is excess keratan-sulfate in urine which differentiates from Hurler's. Normal intelligence which also differentiate from Hurler's. It is short trunk dwarfism with universal platyspondyly with anterior central beaking which is different from Hurler's (fig. 6abcd). There are widened disc spaces. Frontal bossing in the skull with normal sella and depressed nasal bridge. This is also different from Hurler's. There is delayed appearance of ossification centers.

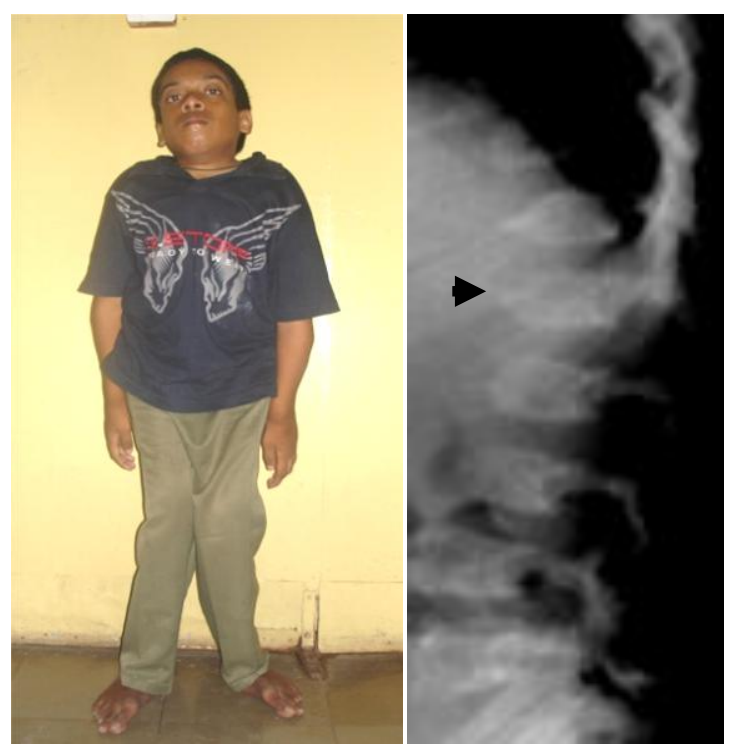

Fig. 6ab: Morquio - 19 Y/M with platy spondyly

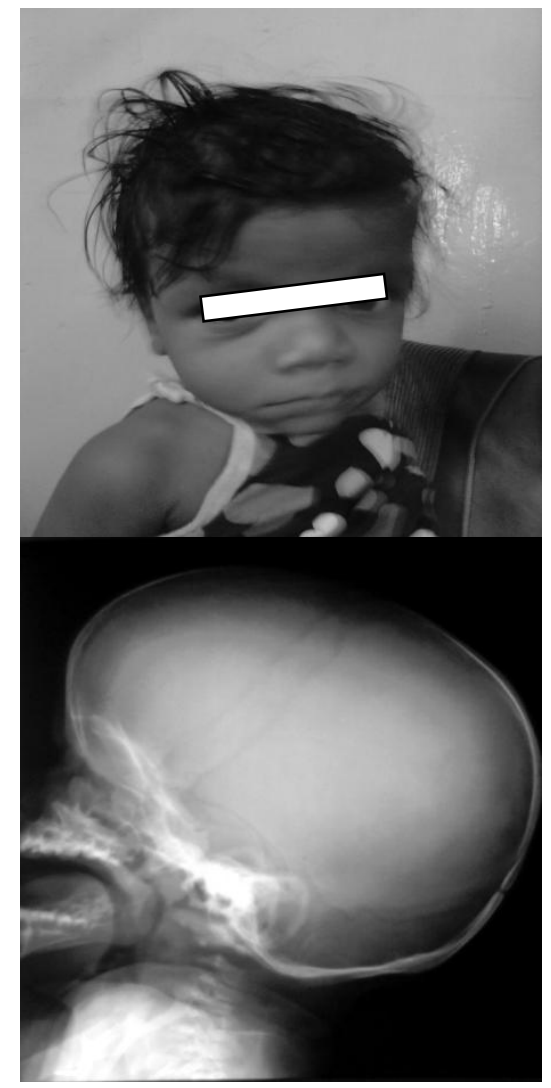

Fig. 6cd: Morquio - c. 3Y/F with depressed nasal bridge, d-Skull, normal sella with dolichocephaly.

Hurler syndrome - MPS 1 is next common disorder. The affected child is mentally retarded. Radiographic features include "J" Shaped sella with platyspondyly and inferior beaking of the vertebra (fig. 7abcde).
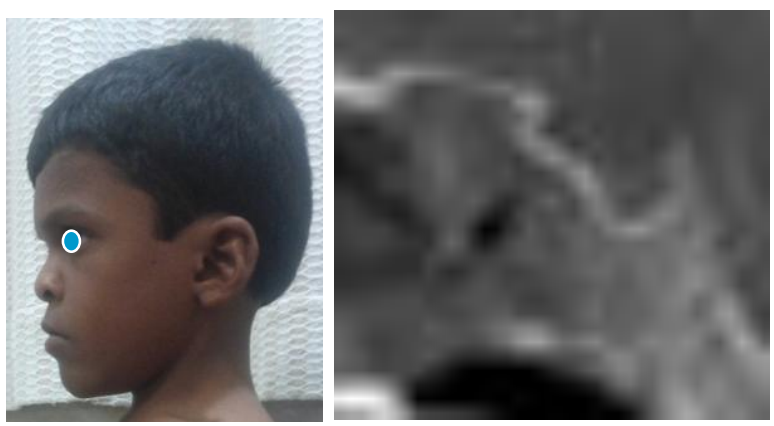

Fig. 7ab: Hurler - 10 Y/M with "J" Shaped sella

The other six types of Mucopolysaccharodosis show varied clinical features with different enzymes in the urine. Radiological features are not as distinctive as Marquio and Hurler. 


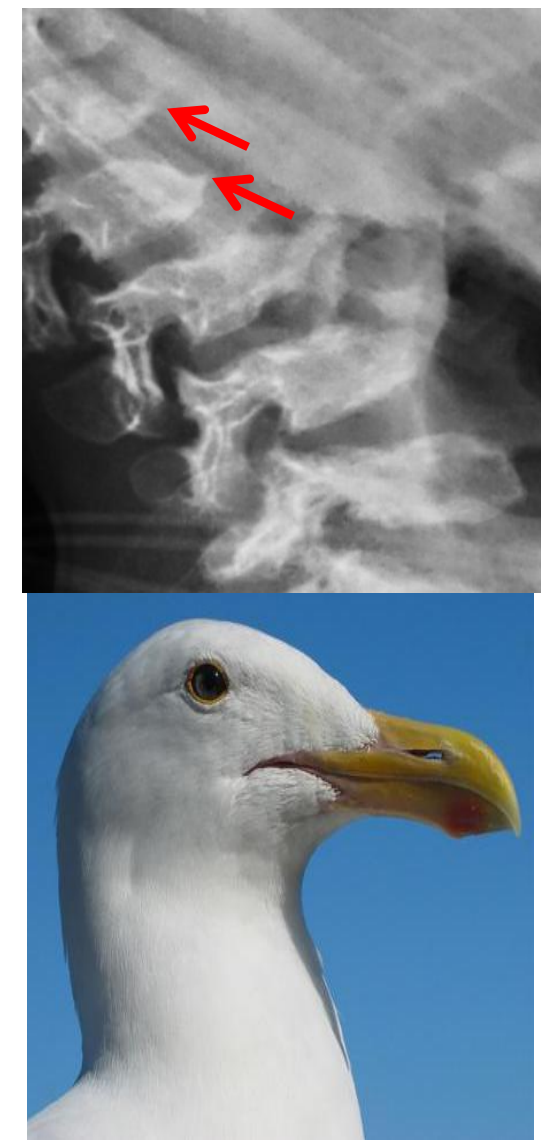

Fig. 7cd: Hurler - Platyspondyly with inferior beaking.

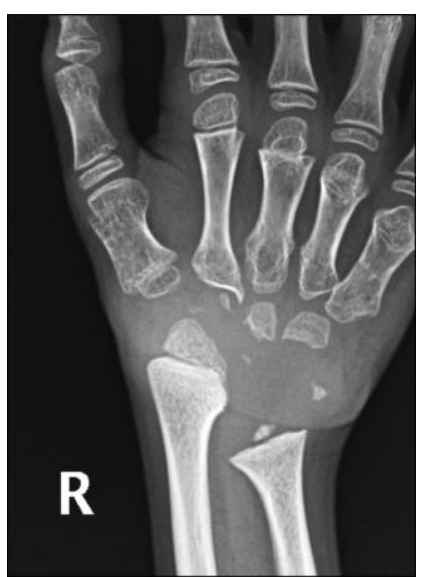

Fig. 7e: Hurler - Hand shows tilting of the ulna towards and bullet shaped proximal ends of metacarpals

\section{Spondyloepiphyseal Dysplasia (SED) - Congenita (Figs. 8)}

Children are of normal intelligence, mild lordosis with short spine. The limb bones are long.

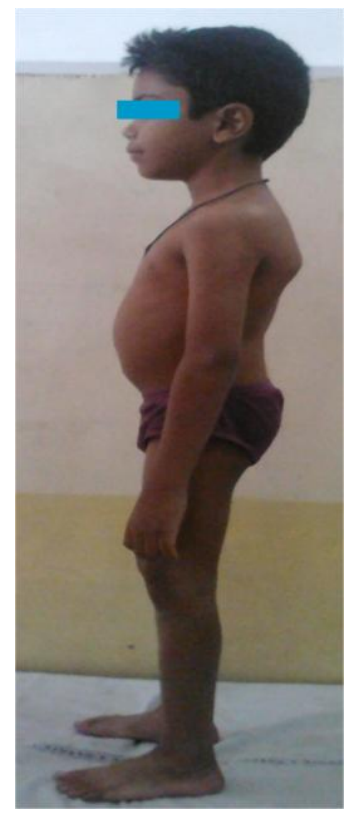

Fig. 8: SED

\section{Spondyloepiphyseal Dysplasia - Tarda}

Radiologically, platy spondyly is noted with a posterosuperior hump in the vertebral bodies (Fig. 9).

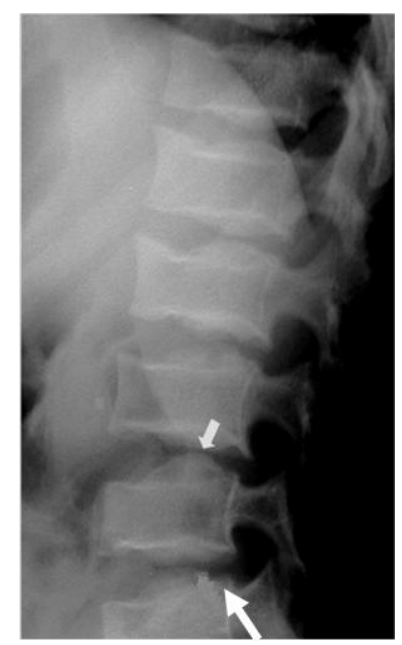

Fig 9: SED Tarda - The postero superior hump is characteristic.

\section{Spondyloepiphyseal Dysplasia with Perpheral Arthropathy}

In several SED patients the peripheral joints of hands and feets are also involved. Radiologically the metacarpal and metatarsal heads are larger with osteoporosis of the bones simulating rheumatoid arthritis. Hence, some authors called is Pseudo- 
rheumatoid spondyloepiphyseal dysplasia (fig. 10).

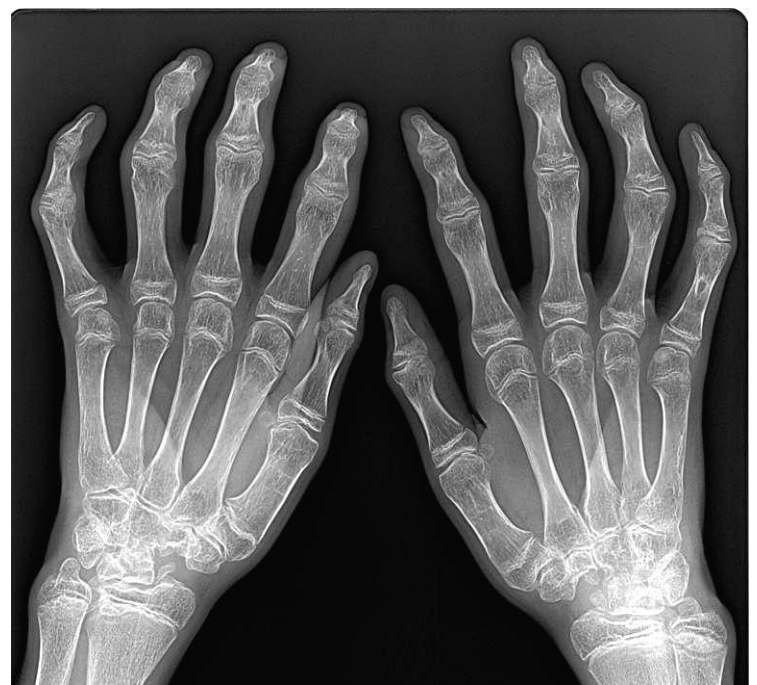

Fig. 10: SED with peripheral arthropathy simulating rheumatoid arthritis.

\section{Spondylo Metaphyseal Dysplasia (SMD):}

The children are of short stature with normal intelligence. Radiologically, platyspondyly is noted with irregularity of the metaphysis and anterior beaking. The articular margins are irregular (fig. 11). In the wrist the findings may simulate healing rickets (fir. 12ab).

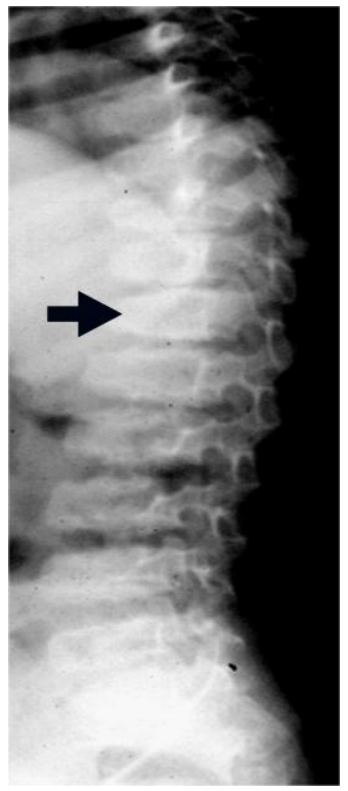

Fig. 11: SMD - Platyspondly with anterior beaking and irregular articular margins.

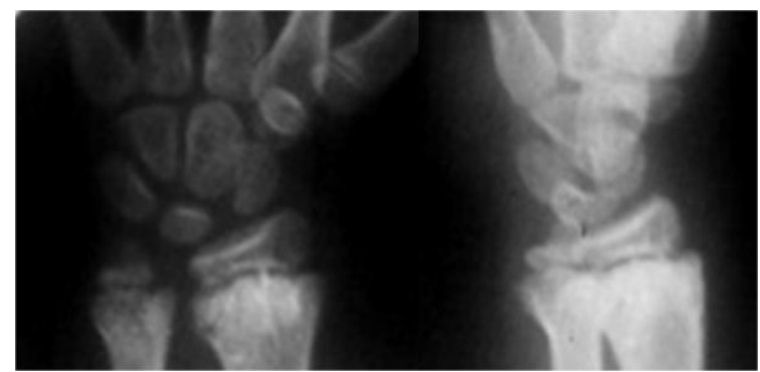

Fig. 12ab: Metaphyseal dysplasia without involvement of the spine.

Platyspondyly - Flat Vertebral Bodies in Congenital Causes - Table IV

Table IV

1. Infantile

- Thantophoric dwarfism

- Metaphoric dwarfism

- Osteogenesis imperfecta type 2

2. Childhood

- Morquio's \& Hurler's

- Spondyloepiphyseal dysplasia congenita

- Spondyloepiphyseal dysplasia tarda

Acquired causes of platyspondyly are noted in Table V

\section{Table V}

Acquired - Malignant Disorders

\section{Multiple myeloma}

- Metastatic Disease

- Round Cell Tumors

- Leukemia

\section{Benign Disorders}

-Histiocytosis X

-Infection ( TB)

-Trauma

-Steroids

-Hemangioma

-Paget's

-Kummel's 


\section{Spondyloepimetaphyseal Handigodu (South India)}

Handigodu disease is a new syndrome of familial spondyloepimetaphyseasl dysplasia. It is inherited at an autosomal dominant trait. The disease is prevalent in Hundigodu village in Karnataka, South India. This is one of the monogenic disorders. On the basis of detailed clinical, anthropometric and radiological investigations of 234 effected individuals, a new diagnosis is reported. Hypocalcitonemia is noted. Radiologically, a spectrum of deformities is noted in the joints, particularly in the hips and vertebral column (Fig. 13abc).

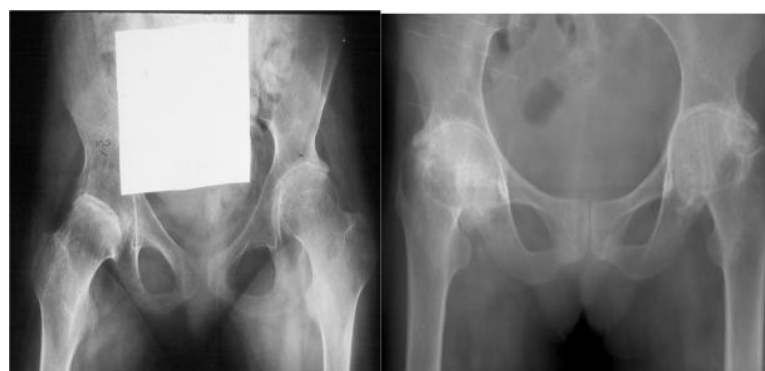

Fig. 13ab: Spondyloepimetaphyseal Dysplasia - Degenerative changes in the joints with dysplastic femoral heads and necks.

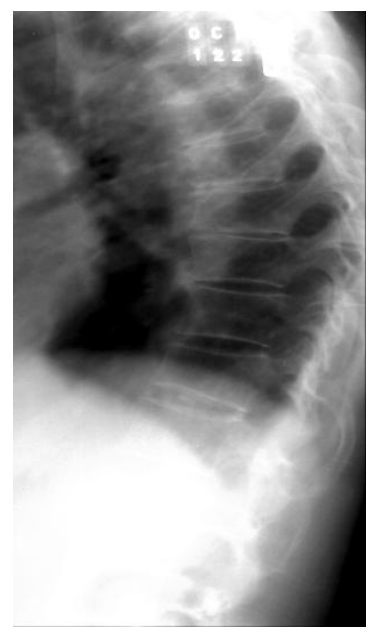

Fig. 13c: - Spondyloepimetaphyseal dysplasia - Premature degenerative changes in the vertebrae with kyposis.

\section{Osteogenesis Imperfecta - Congenita}

There are four types

- I - Mild, Blue sclera

- II - Perinatal, Lethal

- III - Uncommon - Severe

- IV - Uncommon - Resembles 1

Radiological features include a variable spectrum. Intra uterine recognition by ultrasound is known. Radiological features include fractures, lucent bones, unossified skull bones with Wormian bones (fig. 14a). Basilar impression is often noted. Popcorn mineralization is rarely observed in old fractures (fig. 14b). Fractures of long bones with abundant callus are noted (fig. 14cd). The spine shows compressed fractures (fig. $14 \mathrm{e})$.

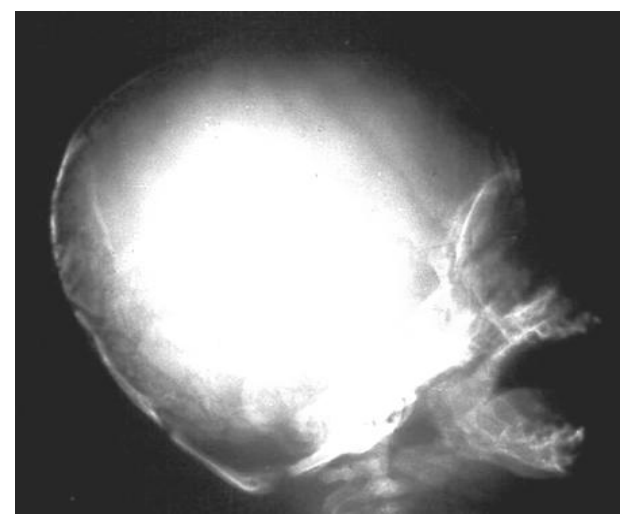

Fig. 14a: OI - Wormain bones.
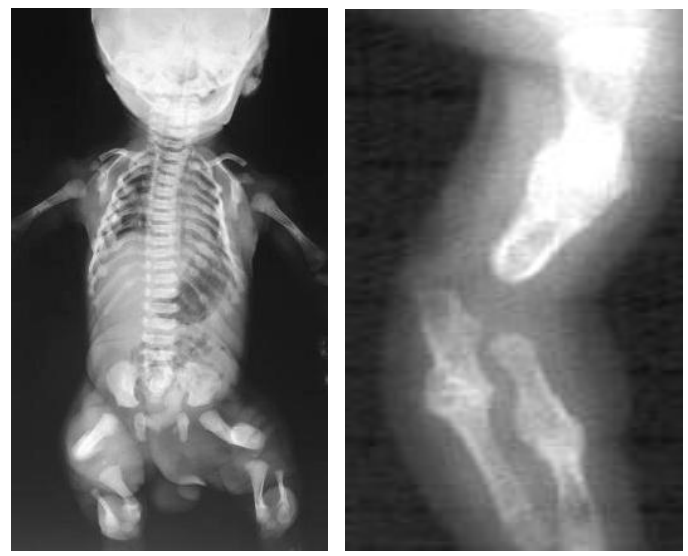

Fig. 14bc: OI Congenita - bc- Healed fractures. 


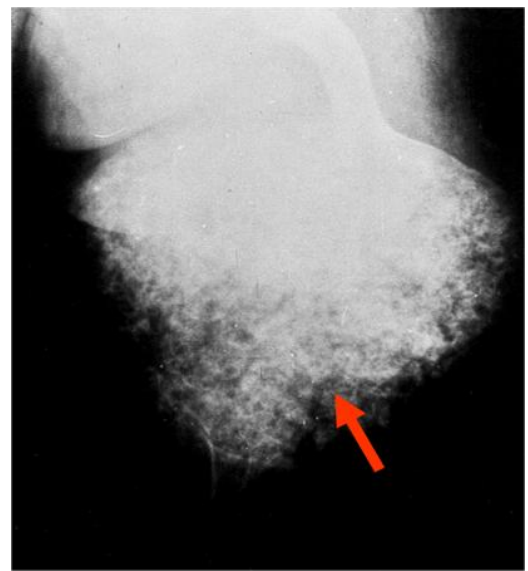

Fig. 10d: OI - "Popcorn" calcifications.

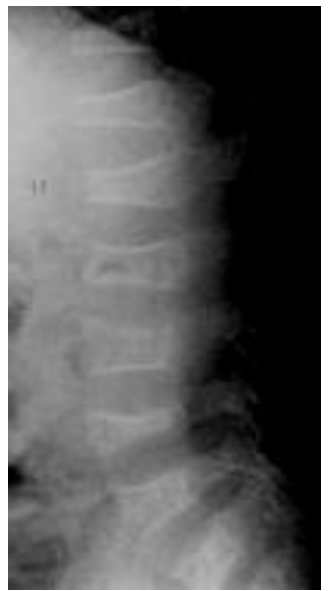

Fig. 14e: Osteogenesis imperfecta Platyspondyly.

\section{CLEIDOCRANIAL DYSPLASIA}

The children are of short stature generally with normal mentation. Radiological features include wide anterior fontanelle, hypoplastic I absent clavicles and mid line defects. These features are similar to pycnodysostosis except the bones are not dense (fig. 15ab).

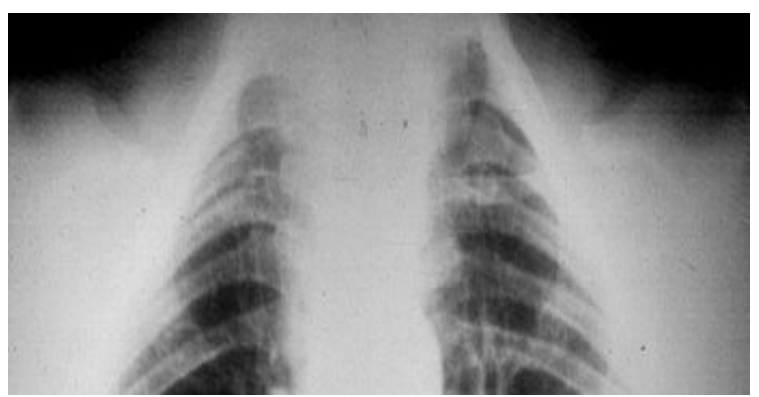

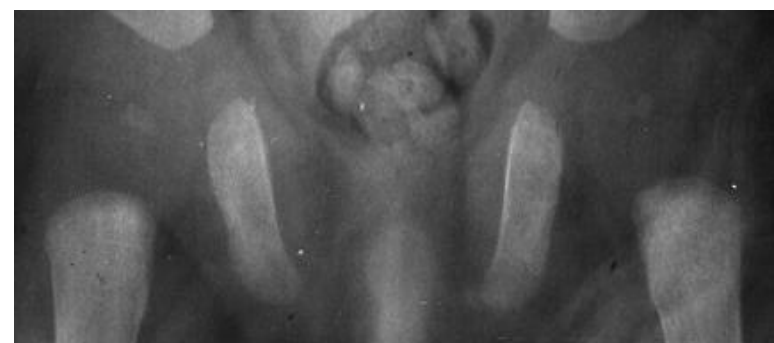

Fig. 15ab: Cleidocranial dysplasia - a. partial absence of clavicles, b. defective pubic bones with separation of ischia.

\section{Chondrodysplasia Punctata - Conradi- Hunermann Syndrome}

It is of two types, one is autosomal dominant with heterogenous expression \& normal life expectancy. Radiological features include Epiphyseal dysplasia.

Punctate or stippled calcification of multiple epiphyseal centers and can be diagnosed in utero during the 2 nd \& 3 rd trimesters by ultrasonography.

The second form is autosomal recessive which is potentially lethal with symmetrical limb shortening contractures of joints, mental retardation, optic atrophy, cataracts and high arched palate. Radiological features are same as form one (fig. 16ab).
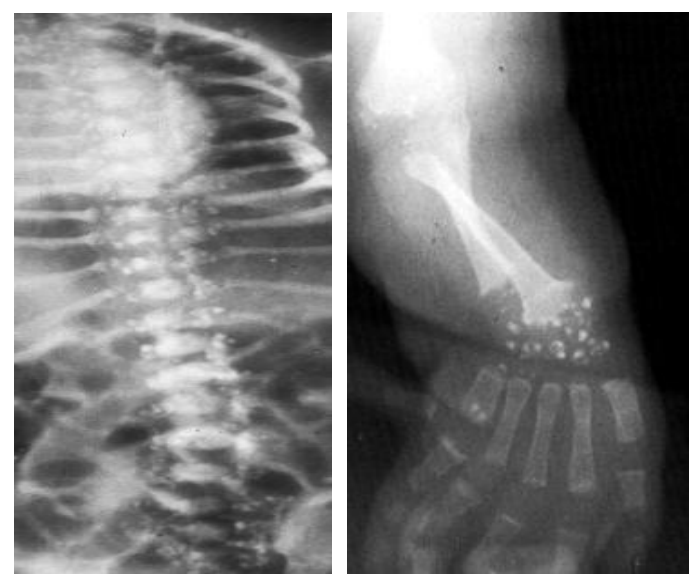

Fig. 16ab: Chondrodysplasia punctataNote calcifications adjacent to vertebrae with vertebral deformities, b-Punctate calcifications in the wrist. 


\section{Chondroectodermal dysplasia (Ellis-Van Creveld syndrome)}

Clincially, short limbed dwarfism with ectodermal dysplasia, polydactyly and congenital heart disease. Absent hypoplastic nails, dysplastic teeth and upper lip anomalies.

Radiologically, polydactyly, syndactyly and syncarpus in the hand (fig.17ab). Long bones are short. Heart anomalies include ASD or single atrium.
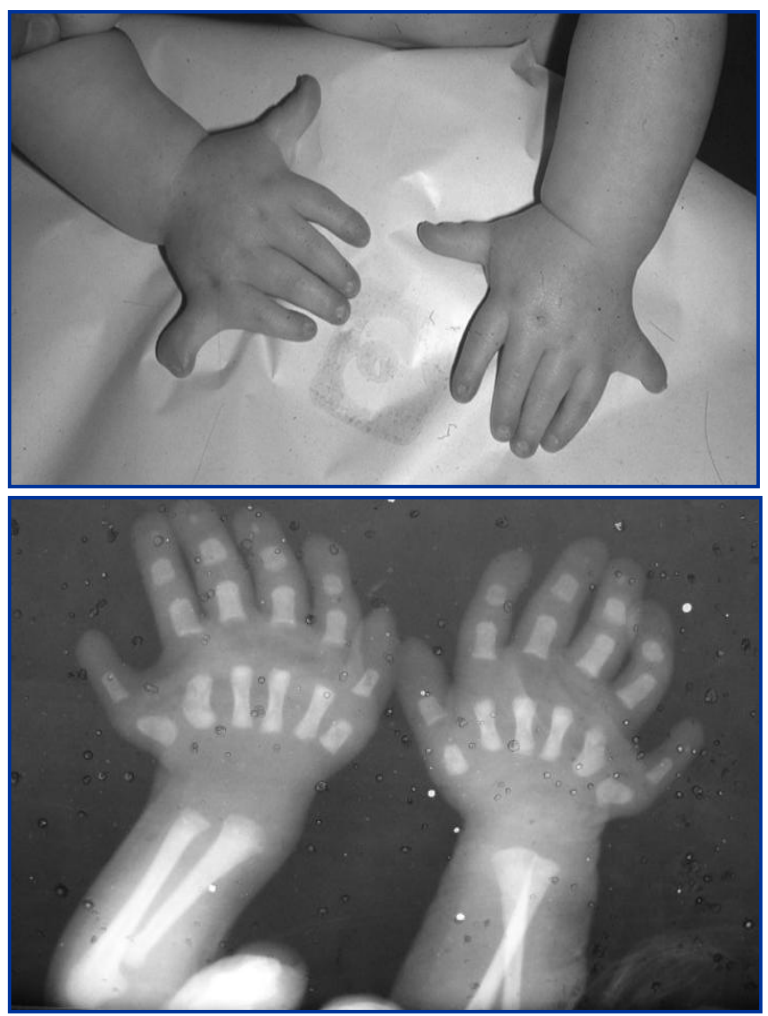

Fig 17ab: Chondroectodermal dysplasia -

a. Clinical polydactyly, b. Radiological polydactyly.

\section{Acroperipheral Dysostosis}

A rare entity with short bones of the hands and feet. No other abnormalities are noted. radiologically, short metacarpals and phalanges are noted (Fig. 18).

Fibrous dysplasia is the most common dysplasia which is a mixture of sclerosing and nonsclerosing types. This entity will be dealt in the next article.

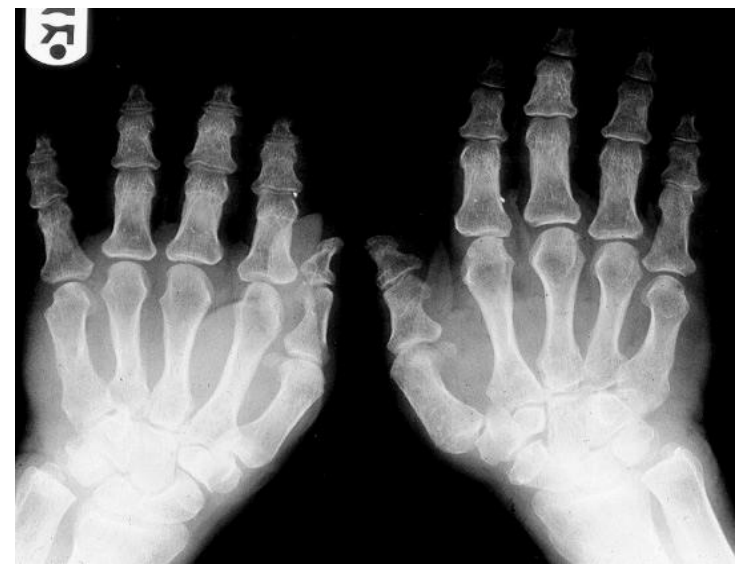

Fig. 18: Acroperipheral Dysostosis - Note the short bones of both hands.

\section{Summary}

Non - sclerosing dysplasias constitute a spectrum of disorders including dysplasias, enzymatic disorders and dysostoses. Some are lethal and can be diagnosed by ultrasonography of the fetus. Radiological characteristics of various disorders are described and illustrated. A rare variety of spondyloepimetaphyseal dysplasia, Handigodu disease from India is also included. Genetic studies and enzymatic studies are essential for proper diagnosis and prognosis, genetic counselling is very important.

\section{Further Readings}

1. Agarwal Ss, Phadke SR, Phadke RV, Das SK, Singh, GK, Sharma JP, Teotia SP, Saxena BN. Handigodu disease: a radiological study, A new variety of spondyloepi (meta) physeal dysplasia of the autosomal dominant type. Skeletal Radiol.1994; 23:611-9.

2. Aegerter,E \& Kirkpatrick JA junior, Orthopedic diseases 1968;175-178.

3. Amaka C. Offiah and Christine M. Hall, Radiological diagnosis of the constitutional disorders of bone. As 
easy as A,B,C?, Pediatr Radio (2003)

33:153-161.

4. Beighton $\mathrm{P}$, et al. International Nomenclature of Constitutional Diseases of Bone. Revision, May, 1983. Ann Radiol (Paris) 1983; 26(6):457-62.

5. Cremin BJ: Infantile thoracic dystrophy. Br J Radiol 199:43, 1970.

6. Kozlowski K, Beighton P. Gamut Index of Skeletal Dysplasias: An Aid to Radiodiagnosis. Berlin: Springer-Verlag, 1984:182-189.

7. Mallikarjun Badadani, $\mathrm{K}$ Taranath Shetty, and SS Agarwal: Hypocalcitonemia in Handigodu Disease: a spondylo epi (meta) physeal dysplasia: nt J Clin Exp Med. 2010; 3(2): 115-121.

8. Murray RO, Jacobson HG: The radiology of skeletal disorders. 3rd ed. Churchil-Livingstone, Edinburgh 1990.

9. Spranger JW, langer LO, Wiedeman HR: Bone dysplasias. An Atlas of constitutional disorders of skeletal development. Philadelphia, WB Saunders 1974; 254:68-85.

10. Subbarao K \& Chudamani $\mathrm{P}$ et al, Chondroectodermal dysplasia, Indian J of Radiology 1963;17(2):51-54.

11. Taybi H, Lachman RS. Radiology of syndromes, metabolic disorders, and skeletal dysplasias. (4th ed.) Chicago: Year Book, 1996. 